\title{
Will Minimal Group Membership Affect Individuals of Different Ages' Tendency to Obey Instructions to Act Negatively Towards a Target (Who is in a Novel Ingroup versus Outgroup)?
}

\author{
Hao Zheng
}

Chinese International School, Hong Kong SAR

zoeezhengg@gmail.com

\begin{abstract}
Stanley Milgram's experiment on obedience to authority in 1961 aimed to investigate the reasons behind acts of genocide and war. Taking inspiration from this experiment, the paper's literature review synthesises research from Stanley Milgrim, Yarrow Dunham, Judith Smetana and many other researchers to present an in-depth acknowledgement of ingroup favouritism, obedience, and the variations in behaviour between different age groups and circumstances. Then, the research proposal aims to investigate the two following questions: will minimal group membership affect individuals' tendency to obey instructions to act negatively towards a target (who is in a novel ingroup versus outgroup)? Does the level of obedience differ between adults and teenagers?
\end{abstract}

Keywords: ingroup favoritism, bias, conformity, authority, obedience

\section{INTRODUCTION}

From concepts such as conformity to the bystander effect, studies of humans reveal we behave in fascinating ways within group contexts. This paper will specifically investigate the concepts of ingroup favouritism, obedience, and the variations in behaviour between different age groups in these contexts. A research proposal will be presented after the literature review regarding the two following questions: will minimal group membership affect individuals' tendency to obey instructions to act negatively towards a target (who is in a novel ingroup versus outgroup)? Does the level of obedience differ between adults and teenagers?

\section{OBEDIENCE IN THE MILGRAM EXPERIMENT}

The Holocaust, the Rwandan Genocide and the Cambodian genocide, these massacres are all results of people issuing commands from a position of authority. How are these authority figures able to convince a large group of not only soldiers to commit mass murder, but also ordinary citizens? Stanley Milgram's experiment, most commonly known as Milgram's Experiment, aimed to justify the reasons behind these acts of genocide, and so the topic of obedience and disobedience to authority arises (McLeod, 2017 [1]). In the experiment, subjects who were all male adults - were commanded by an experimenter to shock a target (Milgram, 1965, p. 59 [2]). Obedience in Milgram's experiment is defined as when "a person does what another person tells him to do" (p. 58 [2]). Milgram measured the obedience of these men to the commander's orders according to the level of voltage that they would shock a target by using a shock generator with 30 lever switches in a horizontal line, each having increasing voltage levels from 15 to 450 (p. 60 [2]). The experiment found that there is overall a high average in the level of obedience within the adult males that participated (p. 72), serving as a justification for the reasons for genocides, in which adult males were the specific targets of these commands.

\subsection{Obedience in Teenagers}

Teenagers are stereotypically known for being rebellious, impulsive, and disobedient, but it is often said 
that young people are more susceptible to persuasion and manipulation. How would teenagers and adolescents act under an authority's orders, and under what circumstances will they obey or disobey? Research conducted by Mitri Shanab and K Yahya (1977 [3]) tested children's obedience using procedures similar to Migram's experiment. The age groups that participated include 6-8, 10-12, and 14-16 years old. According to the World Health Organisation (n.d. [4]), individuals aged from 10-19 years old are categorised as adolescents, while individuals who are 15-24 years old are categorised as young people. Shanab and Yahya's experiment revealed that $73 \%$ of the participants continued to deliver the shock until the highest voltage, and that there were no variations of obedience between the age groups involved, indicating that the obedience amongst children and adolescents is very high as well (1977, p. 530 [3]). Since there are not many existing studies that directly compare children and adults in the context of Milgram's experiment, it would be difficult to compare the obedience between these two groups based on several separate experiments. However, research by Judith Smetana in 1988 shows that children's judgement towards parental authority peaks during their childhood but then declines when they become adolescents (p. 321 [5]). Therefore, it would be reasonable to assume that susceptibility to parental authority or age hierarchy declines as a person grows older, since when people age, they tend to become more independent and less influenced by the age hierarchy.

\section{INGROUP FAVORITISM}

It is only natural for us humans to categorise. Whether it is objects or other people, we tend to implicitly start to sort others and ourselves into groups. Yarrow Dunham (2018a, p.1 [6]) states that "intergroup cognition only arises when we begin to sort individuals into kinds," and these "categories can be thought of as primary constituents of mental life, atoms from which communication and culture are composed." The ingroup, which can be defined as "one's own social categories," is perceived as more positively or "responded to more favorably than members of other social categories," which are often defined as the outgroups (Brewer, 2017, p.90 [7]). Notably, the bias towards one's ingroup is not rooted from the fact that they like the people in their group or any other specific traits that characterises the group; instead, it is from the concept of "mere membership" (Dunham, 2018b, p.780 [8]), where these "social categories" are only categories and do not rely on social positions such as wealth or appearance (Dunham, 2018a, p. 1 [6]). Ingroup bias is prevalent even when there is not any conflict, competition, or any specific information regarding the categories presented (Dunham, 2018 b, p.781 [8]). What is interesting about this is how it is tested with the minimal group paradigm, where people are allocated into groups randomly with "arbitrary cues" such as colours or "novel lable[s]" (Mullen, Brown, and Smith 1992 [9]). Even in these situations, participants show clear signs of ingroup bias although they barely understand any traits that would make their own group superior to others (Mullen, Brown, and Smith 1992 [9]).

\section{TERMS}

It is important to define some terms in the research proposal. The ingroup is the group that a participant identifies themselves as being a part of. The outgroup is the group that a participant does not identify themselves as being a part of.

\section{PARTICIPANT SAMPLING}

The subjects of the experiment will be from two different age groups: teenagers aged from 13-18 years old, and adults aged 45-50 years old. Since the experiment will investigate the variations in obedience within different age groups, these age ranges are far apart and thus will allow the experiment to make valid conclusions about the effects of age on obedience. Moreover, the sample will consist of Chinese people or those who live in China, both in rural and urban areas. The education and lifestyle in these two areas vary and it is believed that the obedience level will also change in relation to the area of residence. The experiment will be advertised on popular social media platforms in China such as Weibo or WeChat to obtain a volunteer sample. The outreach of social media would be greater and therefore would be able to help obtain a larger sample size for the experiment.

\subsection{Design}

The experiment would use the 2 by 2 mixed design with 2 independent variables:

1. Target minimal group membership (ingroup vs outgroup)

2. Participant age (adult vs teenager)

The dependent variable would be the level of obedience to instructions to take/deduct money from a target.

The participants will be separated into four groups:

1. Group 1 will consist of teenage participants paired with an ingroup member.

2. Group 2 will consist of teenage participants paired with an outgroup member

3. Group 3 will consist of adult participants paired with an ingroup member

4. Group 4 will consist of adult participants paired with an outgroup member 
Table 1. $2 \times 2$ design of the experiment

\begin{tabular}{|l|l|l|}
\hline & IV1 (MGM): Target in Ingroup & IV1 (MGM): Target in outgroup \\
\hline $\begin{array}{l}\text { IV2 (Age) } \\
\text { Teenagers }\end{array}$ & $\begin{array}{l}\text { 1: Target in ingroup, Participants are } \\
\text { teenagers }\end{array}$ & $\begin{array}{l}\text { 2: Target in outgroup, Participants are } \\
\text { teenagers }\end{array}$ \\
\hline IV2 (Age) Adult & $\begin{array}{l}\text { 3: Target in ingroup, Participants are } \\
\text { adults }\end{array}$ & $\begin{array}{l}\text { 4: Target in outgroup, participants are } \\
\text { adults }\end{array}$ \\
\hline
\end{tabular}

\subsection{Controlled variables}

The experiment will have 4 controlled variables. The first one being the person giving commands. In relation to the age hierarchy in Chinese society, the commanders participating in the experiment will be male adults similar in age and outer appearance. This is just to eliminate the possibility of bias, since if there is a younger female experimenter or an older male experimenter, there could be a variation in obedience amongst participants. The second controlled variable will be the distance between the participant and the target. In Milgram's experiment, there was an alternative study where the independent variable was the distance between the target and the participant (Milgram, 1965, p.62 [2]). The alternative study resulted in different results from the original experiment as the immediacy of the victim had affected the participant's obedience level, where the further the distance between the two resulted in less obedience (p.62 [2]). Therefore, the participant and the target will be placed in separate rooms throughout the experiment. The third controlled variable will be the location of the commander. In Milgram's experiment, another alternative experiment observed the obedience level in participants when the location of the authority was changed (Milgram, 1965, p.65 [2]). The obedience level in participants decreased when the commander was absent in the room during the experiment (p.65). Hence, in this experiment, the commander will be stationed inside the room throughout the experiment. The last controlled variable will be the answers from the target. Just like Milgram's experiment (1965, p.61 [2]), the target's responses will be standardised and played on an electronic speaker placed in a separate room from the participants. This variable is controlled so that there will not be differences in obedience according to the number of incorrect responses, or according to the type or the wording of the responses.

\subsection{Procedure}

The subjects will meet individually with the experimenters, and they will be allocated into their novel groups. The samples from different locations (rural and urban) in China, and both genders will be evenly distributed within these two groups. The groups will be named with nonsense words: "kam" and "sen." Then, there will be a fake brief before each trial. The participant will be told that they are participating in an experiment to investigate how much knowledge Chinese people have on world history. They are told that people on both teams will be given the opportunity to participate in the question answering process as well. Then the participant will be told that the person answering the questions is given 800 $\mathrm{RMB}$, in which the total amount will be reduced only if that person answers a question incorrectly.

The person who is answering the question will be referred to as the target (the electronic speaker), and the authority figure will be referred to as the commander. The participant will go into a room where they will be provided with a laptop, and they will be informed that they are paired with someone from their own group (ingroup) or someone that is not from their group (outgroup). They are told to record and keep track of the amount of money that the target loses. The commander will order the participant to deduct money every time the target answers a question incorrectly. The design of the questions will be extremely difficult and absurd to make the participant think that it is unfair for the target when they get a question wrong, this will be one of the factors for his/her potential disobedience. For example, the target will be asked "where is John Kennedy from?" The only correct answer will be "the United States of America," so that even if the target correctly answers "the US," it will be deemed incorrect and the participant will be ordered by the commander to deduct money. Google sheets will be used to record the amount, and the laptop will be placed so that the commander in the room will not see it to give the participant chances to disobey. Obedience in this experiment will be demonstrated when the participant deducts money according to the number of 
questions that the target answers incorrectly, and disobedience will be when the participant does not deduct money or adds money to the total amount.

\section{PREDICTED RESULTS}

There are 2 experimental hypotheses:

1. If the age of the participant is younger, they will show higher obedience in comparison to adults to obey instructions.

2. they will show more obedience when it comes to an outgroup member

It is predicted that teenage participants would be more obedient because of the age hierarchy, so they will be more affected and intimidated by the orders from the commander. Since the commander in the experiment will be an adult, the adult participants will be less obedient since they are not affected by the age hierarchy. Moreover, It is predicted that the participants will show less obedience when it comes to an ingroup member, and this will be prevalent in both age groups. This is because of mere membership and the minimal group paradigm which suggests that participants will favour the ingroup, resulting in less deducted money (Mullen, Brown, and Smith 1992 [9]).

The graphs for the experiments hypotheses are presented below:

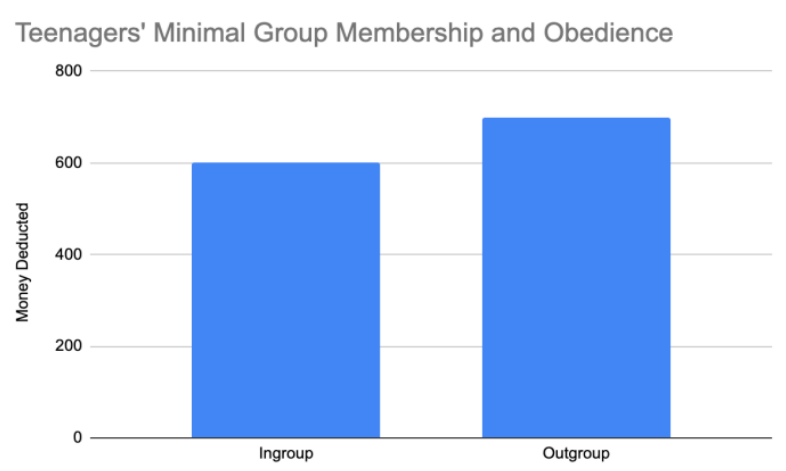

Figure 1. Graph of Experimental hypothesis: Teenager's minimal group membership and obedience

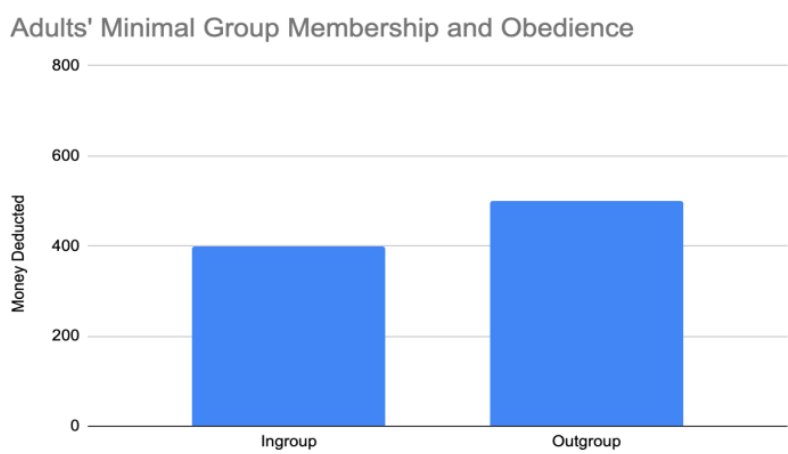

Figure 2. Graph of Experimental hypothesis: Adult's minimal group membership and obedience
The obedience for ingroup relationships is lower for both adults and teenagers. Moreover, adults are showing less obedience in general compared to teenagers. These results would confirm the hypotheses and imply that the minimal group paradigm is indeed valid, and a more general interpretation is that younger individuals are more susceptible to manipulation and persuasion, which is a recurring phenomenon in our society today.

The 2 alternative hypotheses:

1. If the age of the participant is younger, they will show lower obedience in comparison to adults to obey instructions.

2. They will show more obedience when it comes to an ingroup member, that is, they will deduct more money when they are paired with ingroup targets

The alternative hypothesis, however, is not supported by current research. Age hierarchy is reversed to younger participants being in the higher position. Moreover, ingroup bias or the minimal group paradigm is also challenged as the participants will be more favourable to the outgroup instead of the ingroup.

The graphs of the alternative hypothesis is presented below:

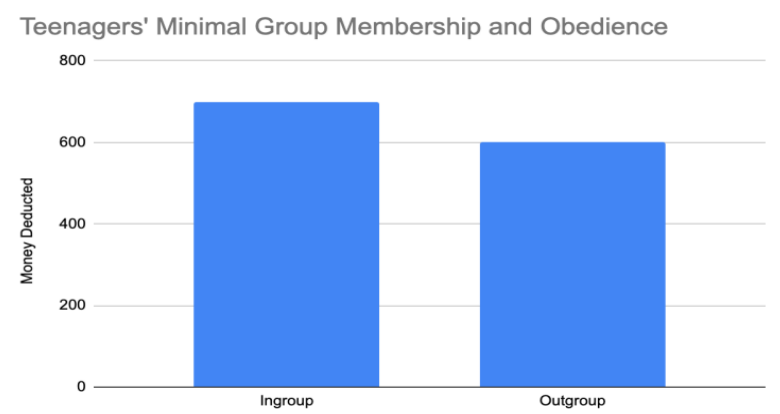

Figure 3. Graph of Alternative hypothesis: Teenager's minimal group membership and obedience

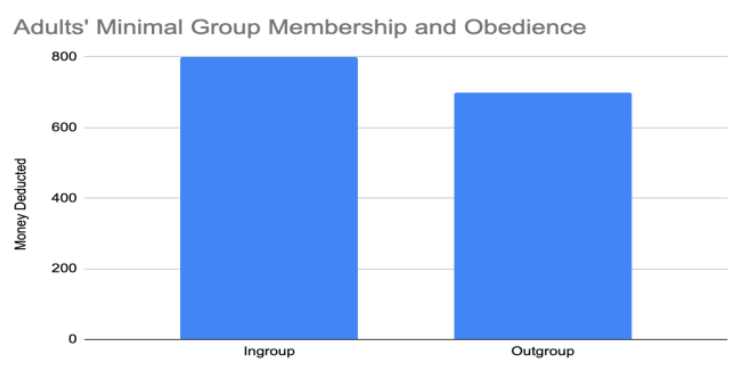

Figure 4. Graph of Alternative hypothesis: Adult's minimal group membership and obedience

The obedience shown when the participant is paired with an ingroup member is generally higher, while the obedience in adults is higher than teenagers. This would not support both the concept of age hierarchy and the minimal group paradigm. It also implies that adults are more susceptible to authority than teenagers. However, 
the trend with adults' obedience higher than adolescents' is not necessarily supported by past research.

\section{STATISTICAL ANALYSIS}

To see whether there is a statistical difference between groups, a t-test will be conducted to compare the means of the sets of data.

There will be 4 t-tests conducted:

T-test 1: Compare mean money deducted in Group 1 versus Group 2

T-test 2: Compare mean money deducted in Group 3 versus Group 4

T-test 3: Compare mean money deducted in Group 1 versus Group 3

T-test 4: Compare mean money deducted in Group 2 versus Group 4

\section{LIMITATIONS OF THE STUDY}

The sample is from the Chinese population, which is only a single nationality. The cultures between different countries vary since people live under different political systems and receive different types of education. Limiting the scope of research to a single nationality would indicate that the results cannot be generalized to the entire human population. One improvement for this limitation would be to alter and extend the sample size to other countries.

The second limitation is the critical level of the experiment. The experiment is designed based on the Milgram experiment conducted in 1965, in which the participants were ordered to deliver high voltage shocks to the victim in the experiment. This caused mental distress in participants which was one of the key factors to their disobedience. However, in this experiment, because of ethical reasons, the participants would only feel uncomfortable instead of distress, so this may have influenced their decisions to obey or disobey. However, severity of their actions would give more valuable results for the experiment, and would justify the more extreme situations such as mass murder that the Milgram experiment had investigated. This limitation would be difficult to improve considering the ethics of the experiments, since often forcing participants to commit severe actions would be unethical and harsh.

The third limitation is the ethical concerns regarding the consent from the participants. It is unethical for experimenters to conceal true intentions of the experiment from the participants when asking for their consent to participate. This would invalidate the experiment's ability to accrue data. However, the experiment cannot work without deception, since it is essential to retrieve accurate and unbiased information.

\section{FURTHER INVESTIGATIONS}

There can be alternative experiments conducted in relation to this experiment. The first one could be to investigate how the time that the participants were given to deduct money would affect their obedience. This also investigates the level of impulsiveness in different age groups. There can also be an investigation based on the gender variations of the participants and the commander. It would be interesting to see how the gender and age of the participants would affect their obedience, and how the gender of the commander would affect the obedience observed.

\section{CONCLUSION}

The experiment based on the obedience and group membership of participants would reveal how the age and minimal group paradigm contributes to the overall behaviour of people. The experimental results would reflect the evident phenomenons of age hierarchy and susceptibility to authority present in our society today. Ultimately, these experiments uncover some of the underlying reasons of obedience and ingroup favouritism, and how it is significant to understanding human behavior in our society today.

\section{REFERENCES}

[1] McLeod, S. (2017). The Milgram Shock Experiment. Simply Psychology. Retrieved July 20, 2021, from https://www.simplypsychology.org/milgram.html\#: :text=Milgram\%20(1963)\%20examined\%20justifi cations $\% 20$ for,following $\% 20$ orders $\% 20$ from $\% 20$ th eir\%20superiours.

[2] Milgram, S. (1965). Some Conditions of Obedience and Disobedience to Authority. Human Relations, $18(1)$, 57-76. https://doi.org/10.1177/001872676501800105

[3] Shanab and Yahya, M. E. (1977). A behavioral study of obedience in children. Journal of Personality and Social Psychology, 35(7), 530-536. https://doi.org/10.1037/0022-3514.35.7.530

[4] Adolescent health in the South-East Asia Region. (n.d.). World Health Organisation. Retrieved July 22, 2021, from https://www.who.int/southeastasia/healthtopics/adolescent-health

[5] Smetana, Judith G. (1988). Adolescents' and parents' conceptions of parental authority. Child Development, $\quad 59(2), \quad 321-335$. https://doi.org/10.2307/1130313

[6] Dunham, Y. (2018). Intergroup Cognition. International Encyclopedia of Anthropology, 1-7. 
[7] Brewer, M. B. (2017). Intergroup discrimination: Ingroup love or outgroup hate? The Cambridge handbook of the psychology of prejudice, 90-110. https://doi.org/10.1017/9781316161579.005

[8] Dunham, Y. (2018). Mere Membership. Trends in Cognitive Sciences, 22(9), 780-793. https://doi.org/10.1016/j.tics.2018.06.004

[9] Mullen, B., Brown, R., \& Smith, C. (1992). Ingroup bias as a function of salience, relevance, and status: An integration. European Journal of Social Psychology, 22(2), 103-122. https://doi.org/10.1002/ejs

[10] p.2420220202 